\title{
Confessions of a Fieldworker-How I Stratified a Rural Population
}

\section{Mick Howes}

\section{The Rapid Rural Appraisal Conference in 1979}

When I was approached to present a paper for the RRA conference, my initial reaction was negative. As someone who had been trained as a social anthropologist, and who had subsequently been involved in two extended pieces of fieldwork, I was perhaps understandably suspicious of the 'rural development tourist'. From the vantage point of communities which one has come to know quite well, it becomes clear in retrospect, how misleading initial impressions can be; and how easily short term visitors can fall into the trap of asking the wrong questions, or of accepting answers which, at best, only illuminate small areas of complex issues and relationships. From this point of view, the whole basis of RRA appeared to me as unacceptable, and I was tempted to have no more to do with it.

But the request did begin to raise some important question about fieldwork. What considerations influenced the way in which fieldworkers allocated their time? Could the long periods devoted to fieldwork studies really be justified by the outcome, or was there a tendency for the researcher to proceed with particular lines of enquiry beyond the point of diminishing returns in order to satisfy inappropriate standards of methodological completeness? Could the collective experience of fieldwork provide a basis for identifying short cuts, which whilst not satisfying the requirements of the very short term visitor to rural areas, might at least render the process of research more efficient, and reduce the periods of time elapsing between the collection of data and the dissemination of results to wider audiences?

An earlier seminar on RRA had already posed these question in a rather general way, and the answers arrived at were inevitably of a fairly conditional nature. The extent to which more rapid rural appraisal might prove possible would depend upon the quality of records already available; the adequacy of existing theoretical frameworks relating to the specific nature of the problems under investigation; whether or not it was possible to rely on direct observation rather than verbal reports; the sensitivity of the issue being explored where informants were relied upon; and so forth (Barnett 1979). My response to this was to try to investigate more concrete instances of tradeoffs between the quality of data obtained, and the time devoted to its collection, and then to see if more general lessons could be derived. In retrospect, it now seems to me that the question raised was premature, and that the exercise which followed from it largely fruitless; but it is worth recapping briefly on the approach adopted at that stage, since this will help to identify more useful ways forward.

My own paper drew on recently completed fieldwork in Bangladesh, where $I$ had been exploring the consequences of the introduction of a number of small-scale irrigation techniques in terms of levels and patterns of crop production, the distribution of income, and the transformation of social relations (Howes 1979). In order to carry out this research it had been necessary to devise a means of stratifying the population, and I had eventually decided upon an approach which distinguished five social classes. Having outlined the characteristics of these classes, I then proceeded to rework my basic data for one village using simplified criteria of classification, which, if adopted at the outset of my research, would have reduced substantially the period of time required for data collection.

The outcome of this seemed useful only to the extent that substantial divergencies were found in the way in which individual households were classified, when simplified criteria were used. It appeared, in other words, that large, and by implication unacceptable losses in 'accuracy' were entailed by the various short cuts explored, although in the absence of reliable information on the amount of time required for the collection of basic data of varying degrees of complexity, no satisfactory answer to the question of tradeoffs could be advanced.

In conclusion, it proved possible to do little more than suggest that the kinds of procedure used might have applications for future work in formulating methods for pre-testing questionnaires, and were likely to be of particular value where extensive surveys, involving large numbers of respondents, were to be undertaken. It was also noted that whilst the particular problem with which I had been concerned did not appear to be amenable to short-cut solutions, this did not rule out the possibility that more rapid methods might be used under other circumstances.

Other papers presented at the conference (Moore 1979, Longhurst 1979) drew more positive conclusions. But once again, in the absence of information regarding the time taken to gather data or of any detailed discussion of the type of problem to which rapid 
approaches might be applied, these seemed to me to be largely inconclusive.

Discussion at the conference itself centred largely on the question of why the participants most of whom had extensive fieldwork experience, had proved unable to provide more useful and positive advice on potential RRA approaches. A number of possible explanations were advanced. These included the persistence of 'academic values', which emphasised the understanding of social relations; and the separation which followed from this from the sphere of the development practitioner, where the overriding requirement was for immediate action. It was felt, in other words, that academic researchers were largely insulated from the demand to produce results within limited and predetermined periods of time and that whilst this did not preclude the possibility of more active involvement. this was at best of only secondary importance.

But this provided only a partial explanation. A second important dimension of the problem was the relative autonomy of the researcher within the community of fieldworkers, in combination with the professional requirement to appear to carry out research in a manner consistent with sound 'scientific' procedures of enquiry. Fieldwork, typically, was a highly individualistic pursuit, and in practice involved a great deal of 'flexibility', with corners being cut, and problems and approaches frequently reformulated in the light both of experience, and of the limited time available. In many respects, it did raise issues which closely paralleled the concerns motivating the search for rapid methods of rural appraisal; but these were seldom aired in books or articles, where research results would be presented in isolation from all but the most formalistic and rationalised account of how they were actually obtained. This tendency to mystification was reinforced by the practice of throwing research students 'in at the deep end', with little prior discussion of the kinds of decision which they would be obliged to take during the course of their fieldwork; and perpetuated by successive generations who returned from the field with a vested interest in not revealing the manner in which they had actually gone about the business of research.

In principle, it was agreed that these problems could be overcome if relatively more fieldwork were to be carried out by older, more experienced, and more self confident researchers, who would perhaps be less inclined to cover their tracks; but in practice considerations of family and career development meant that the present situation was unlikely to change to any significant extent. A more feasible way forward was felt to lie in collaborative projects, where the logistics of research would be explicitly discussed; where an element of initial experimentation with alternative methods would become a virtual necessity if a coherent approach were to be devised: and where the application of a similar range of methods by different people in different locations, would almost inevitably suggest conclusions regarding the relative efficiency of individual procedures. Under such circumstances, the questions raised in my conference paper might more usefully be explored, and some direct contribution made to the search for RRA methods.

But an important pre-condition to the success of an exercise of this kind, as well as for the more effective utilisation of the time of the individual researcher, was that more should be known about the way in which fieldwork is actually conducted. The "confession" which forms the subject of the rest of this article is intended as a modest step in this direction. My conference paper started with a description of the way in which households were classified, and then proceeded to take this as given (and implicitly correct), and to use it as a basis for assessing the viability of more rapidly executable alternatives. Here, I shall attempt to explore what now seems the more useful and important question of how that classification itself was arrived at.

\section{The Early Stages of Research}

The account which follows is inevitably partial and selective, but should convey at least a flavour of the process involved. To recap, the major purpose of my research as a whole was to compare different smallscale irrigation techniques from the point of view of production, distribution and the transformation of social relations. In view both of my previous lack of experience in Bangladesh and the apparent complexity of the organisation of agricultural production, I decided to confine my attention to one small area, and to work closely with a small research team. In the course of a preliminary two-month visit in 1977. I had identified an area where a number of small-scale techniques were in use, and had already decided that that was where I would work. By May 1979, I had applied for and obtained a grant which would enable me to spend a total of 17 months in Bangladesh, and to engage three research assistants for a 14-month period. In the course of doing this, I had been obliged to spell out in some detail both the central hypotheses by which the research would be guided, and the methods of data collection to be used.

The first three months were to be spent on language training in Dacca and general preparatory work. The 14-month fieldwork period was to be divided between two months of preliminary study, where familiarisation with the area selected would take place, and where a census could be carried out which would provide a sampling frame: and a 12-month period during which production activities could be monitored on a week by week basis. 
Illness and other unanticipated difficulties delayed my arrival in the field by a month. and left only a month for preparation prior to the year of survey work which had to start from the aman crop in early September. The first week was spent in a quick reconnaissance of the area selected. at the end of which it was decided to focus on four hamlets where large numbers of handpumps were in use and where deep and shallow tubewell groups were operating. Following a brief period of pre-testing. a basic census form was devised and administered to the 400 households in the hamlets chosen. This included questions on household size: land owned and/or operated under various tenancy arrangements and area irrigated by different techniques. as well as items designed to determine the approximate degree of engagement in the labour market. either as hirer or supplier of wage labour. during the course of the previous year.

This then provided the raw material for classifying households. and for subsequently drawing-up samples. so that all categories of land operators could be adequately represented in the surveys which followed. The story of how households were classified. and the reasons lying behind this process. continues beyond this point in time. but starts in the period preceding the commencement of fieldwork. It is there that I will begin.

\section{Stratification in National Level Surveys}

One of my initial concerns had been to provide a basis by which at least some of the research findings might be related to the choice of irrigation technology in a national context. As a first step. therefore. I looked at existing national level survey data to see whether there was any commonly agreed method of stratification which might be used. I found that approaches did converge to the extent that the amount of land owned was generally taken as the sole criterion of classification. but that beyond this point there was very little agreement. The widely quoted Agricultural Census (Government of Bangladesh 1980) was based on one set of size intervals. and the influential 'Land Occupancy Survey $(1977)$ on another. with categories continuing to proliferate as further surveys were considered. It quickly became apparent. therefore. that whilst the control of land would ultimately have to be taken into account as an important means of classification. the manner in which this criterion had been employed in most available surveys was arbitrary.

Furthermore. it was apparent that the use of simple land holding intervals would have been subject to serious limitations even if a broad degree of agreement as to the precise intervals to be used. had been found. In the first place. such a classification could take no account of variation in family size and composition. as it lumped together small and relatively well-off house- holds and larger and poorer ones. simply on the basis of equivalence in the absolute amount of land owned. Secondly. it would obscure important regional and sub-regional variations in soil fertility. and subsequently. in level of output. But more fundamentally. a simple landholding criterion could convey no sense of the relations between social classes. or of the manner in which social relations as a whole were reproduced through time.

In spite of these difficulties. there might have been a case for using purely land-based systems of classification if a broad measure of agreement had emerged between existing approaches. Although quite inadequate in itself. this would have provided some indication. for example. of variation in the extent of landlessness and tenancy from one part of the country to another. and this. in turn. might have provided a basis for assessing the extent to which the results obtained in a particular area might have been expected to apply in a wider context. Given the wide variety of categories used however. and the virtual impossibility of assessing the reliability of results obtained in individual cases. this option had to be ruled out.

\section{Production Relations and Social Class}

I next turned my attention to the way in which other fieldworkers had approached the problem of classification. There was a much more strongly developed tendency here to think in terms of production relations. but whilst this in itself seemed desirable. it quickly became apparent that fundamental difficulties remained. In the first instance. these derived from the diversity of relations arising in rural Bangladesh itself. and from the lack of any adequate theoretical framework for explaining the connections between them. Certain writers attached primary importance to the persistence of landlord/tenant relations. and concluded that the dominant mode of production was therefore feudal or semi-feudal in nature. Others pointed to the growing tendency to landlessness. and to the emergence of a small. rich farmer class employing hired labour. as evidence of developing capitalist relations: whilst others still emphasised the continuing importance of independent producers. and spoke of the dominance of a peasant mode of production.

Further layers of disagreement and confusion arose when the area of debate was extended to encompass questions of exchange: both in relation to accumulation within the rural areas themselves. and in terms of

'Not all of the approaches reviewed were subject to this final objection. The Agricultural Census. for example, in addition to the use of landholding intervals, employed an alternative classification distinguishing 'owner operators' from 'part tenants' (who own some land. and took some in sharecrop) and 'pure tenants' (who had no land of their own). But in the absence of any rationale derived from a broader understanding of the relation between social classes, this was accompanied by a similar tendency to conflation on the one hand. and arbitrary distinction on the other. 
wider linkages to the State and the international capitalist economy. Echoes of many of the issues so fiercely contested over many years in the context of the debate on the mode of production in Indian agriculture were, in other words, to be detected in the literature on Bangladesh. Whilst this was in many ways welcome, it was at the same time apparent that the general and rather abstract level at which this debate had been conducted, offered very few useful guidelines for the researcher concerned to generate fresh empirical data. and that there was a depressing tendency to fall back on conventional national survey type data, when evidence was sought in support of one position or another. There were however, notable exceptions.

\section{Patnaik's 'E-Criterion'}

The first of these which 1 considered was Patnaik 's ' $E$ ' criterion (Patnaik 1976), which classified individual households in terms of their 'labour exploitation ratio', or of the 'degree of use of outside labour in relation to the use of household labour. E is arrived at for individual households by the following procedure:

i) the net use of outside labour is calculated by adding the total number of labourers hired directly in the course of a year, to the number of days' labour performed by tenants on a household's land; and subtracting from this the number of days of wage labour performed for others, and the number of days' labour performed as a tenant on the land of others. The result would be positive in the case of net hirers in of labour and negative for net hirers out:

ii) the number of days' labour performed by a household on its own land are calculated;

iii) the net labour used is divided by the amount of labour performed by a household on its own land.

The results are then used to differentiate:

-landlords. where the net use of labour is high, own labour is zero, and $E$ infinite;

rich peasants. where the net use of labour is positive, and greater than own labour, and E positive and greater than 1;

upper middle peasants. where the net use of labour is positive but less than own labour, and $E$ is therefore positive but less than I:

- lower middle peasants, where the net use of labour is zero or negative, but less than own labour, and $E$ is negative but less than 1 ;

- poor peasants. where net use of labour is negative. and greater than own labour, and $E$ is therefore negative and more than 1 :

-labourers. where the amount of labour given is high, own labour is zero, and $\mathrm{E}$ is therefore negative and infinite.

A further refinement is also possible, where the net use of labour through tenancy and direct hiring arrangements is compared, and the household characterised as engaging primarily in relations of a 'feudal' nature where the former is higher, and of a 'capitalist' nature where the balance is reversed.

These procedures are spelt out in some detail because they have very important positive features. In the first place, they make it possible to classify on the basis of actual production relations, and do not rely on access to means of production such as land, as a proxy measure. Secondly, they provide an objective means of determining the relative importance of different forms of production relations in individual cases, as well as at the level of the 'system' investigated as a whole; and as such throw valuable empirical light on the broader question of the dominance of one particular mode of production over another. Thirdly, the categories arising are perfectly discrete which means that the method can be widely applied without the danger of inaccuracies arising through the way in which particular data sets are interpreted by individual researchers.

For these reasons, 1 seriously considered using the $\mathrm{E}$ criterion in my own research, but 1 was eventually forced to reject it on practical grounds. Studies elsewhere had shown that informants' ability to recall accurately the amounts of labour hired declined rapidly only a few days after the event (Moore and Lipton 1972); and since the validity of the $E$ criterion was highly sensitive to the reliability of such data, it followed that it could only safely be applied at the end of a year during which the necessary information had been collected weekly, or on some similar basis. On the other hand, 1 was confronted with the problem of classifying the population in advance of the main period of survey work, so that stratified samples could be drawn, and then used as a basis for the enquiries that were to follow.

\section{Classification in 'Jhagraphur'}

The methods used by Arens and van Beurden in 'Jhagraphur' (1977) imposed less exacting data demands, but still attached central importance to production relations, although used in combination with information on the means of production controlled by individual households. In outline their system distinguished between

-landlords: who control means of production out of all proportion to those required to support their own households, who engage in no manual labour themselves, and who rely exclusively on the labour 
of others. through sharecropping or direct hiring arrangements:

-rich peasants: who own more than sufficient means of production to support their own households. who perform little manual labour themselves. and rely largely on the labour of others through hiring or sharecropping arrangements:

- middle peasants: who own sufficient means of production to make ends meet. hire in labour from time to time. but seldom work for others. and are exploited to some extent by landlords and rich peasants through money lending and tenancy arrangements. This class is, divided in turn. into middle peasants safe-to whom the above clearly applies-and middle peasants in danger, who engage directly in wage labour relations only to a very limited extent but to whom land taken in sharecrop is becoming of increasing importance. and whose land is barely sufficient to eke out a subsistence under normal conditions:

-poor peasants: who own at best very little land. This class is further sub-divided into poor peasants (small), who rely mainly on sharecrop land for their livelihood. and semi proletarians or landless peasants. who rely mainly on the direct sale of their labour.

The Arens and van Beurden classification was somewhat rough and ready. but by contrast with the $E$ criterion. it did appear appropriate to circumstances under which only a limited amount of time was available for data collection. and it was therefore adopted as the best option available. Having completed the basic census outlined above. I then sat down with my research assistants and set about the task of trying to allocate individual households to classes. Poor peasants presented little difficulty. and with one possible marginal exception. it was clear that none of the households fell into the landlord category. The occasional anomaly arose in the form of households headed by women. where small amounts of land owned could be combined with an exclusive reliance on hired labour for tenants: but these cases were too few and far between to constitute a serious problem. Difficulties did. however. quickly become apparent in relation to the substantial number of households lying close to the boundaries between rich and middle peasants (safe). and between middle peasants (safe) and middle peasants in danger.

To some extent these arose through a lack of adequate information about family composition. The basic census form had only enquired about numbers of males and females and had not required households to be broken down sufficiently by age: leading to a situation where cases with very young children and relatively low consumption requirements. could not adequately be distinguished from those where children were older. and the amount of land required for subsistence accordingly greater. A further problem. which would not have arisen to anything like the same extent in Jhagraphur where few modern agricultural inputs were in use. was the precise weight to be attached to the amount of irrigated land owned in determining a household's capacity to subsist. or secure a surplus to its own requirements. In the event. and under the pressure of time. these difficulties could only be resolved in a rather unsatisfactory way. by making crude assumptions about family composition. and the net returns from irrigated and non irrigated agriculture in marginal cases.

As our regular survey work proceeded. and we got to know the people in the area better. further problems began to emerge. In certain instances. landless households had initially told us that they had land. since they had believed that we represented a development agency which would be following the normal government procedures. of only advancing credit to those able to offer land as security. Others. fearing that we were part of a land reform programme. had deliberately understated the amount of land owned: and others still had simply been confused by our census questions and offered information that later turned out to be incorrect.

Fortunately. most of these problems came to light at a very early stage when samples could be adjusted. with little damage having been done. But in other instances. although the data on which they were based proved to be correct. the classifications arrived at did not appear to square with the circumstances of households. as these unfolded during the early months of the survey. This became worrying. and I also became increasingly concerned at the ease with which the data. which we had spent so much time collecting. could ultimately be rejected on the strength of the apparently interpretive and imprecise nature of the methods of classification used.

\section{The Method of Classification Used}

The modified procedure adopted in response to these problems was revised slightly at a later stage. but for the sake of simplicity. I shall describe only the final formulation arrived at here. The initial approach. derived directly from Arens and van Beurden. had given weight to both the means of production controlled and to the production relations entered into: but $I$ now placed a heavier emphasis upon the means of production. in the first instance. In the case of poor peasants - the labourers and tenants. who owned no land - this made no difference. and these classes could still be differentiated from each other simply on the grounds of the dominant production relation in which they engaged. For the landed households. the new procedure for classification was based upon the 
productive capacity of the land owned, in relation to consumption requirements, and worked out as follows:

1. consumption requirements were calculated by:

a) taking the basic caloric requirement of an adult male used in the National Nutrition Survey (1977) and converting this into an annual paddy requirement;

b) calculating the number of adult male equivalents in individual households, by collecting additional data on age composition, and then using coefficients for different sex and age categories, again derived from the National Nutrition Survey;

c) multiplying a by $\mathbf{b}$, to give the total annual paddy requirement.

\section{Food availability was calculated by:}

a) drawing on survey results, to identify the most common cropping pattern prior to the introduction of irrigation, and the average yield of major crops to give average annual net per acre yields expressed as a paddy equivalent;

b) multiplying this figure by the number of acres which a household owned.

3. Availability was then divided by requirement and individual households classified as:

a) rich peasants: where availability was 2 or more times requirement;

b) middle peasants safe: where availability was between 1 and 2 times the requirement;

c) middle peasants in danger: where availability was less than requirement.

The strength of the system was that it provided clear criteria for the allocation of individual cases, and at the same time distinguished between surplus, subsistence and deficit households in a manner which seemed likely to reflect underlying differences in production relations. When this assumption was checked against independent data on production relations it was found to hold good. Rich peasants tended to rely much more heavily on hired labour, and much less on family labour than middle peasants; and among the landed classes, only members of the 'middle peasant in danger' class engaged in wage labour for others, or took land in sharecrop to any significant degree. At the same time, by working out what the situation would have been without irrigation, a basis was provided for a subsequent range of calculations which could then indicate how the introduction of different techniques had influenced the economic status of individual households.

But there were limitations. Neither the variable quality of land, not the tendency for poorer landowners to cultivate their land more intensively under traditional conditions, were taken into account. As with the $\mathrm{E}$ criterion, these were refinements that had to be ruled out in view of the time which would have been required to have explored them adequately. The procedure could also be criticised both on the grounds of the heavy emphasis given to the sphere of production, and within this to land as a means of production. Ideally, other means of production; access to non agricultural employment opportunities; the polarising influence of money lending; and the possibilities for accumulation in the sphere of exchange, should also have been taken into account. Finally the need to revise the classification procedure in the course of the research had an unbalancing effect on the sizes of the samples drawn from different landholding strata, and undermined the statistical validity of any conclusions.

\section{Conclusion}

Others might wish to add further criticisms but the limitations of the method described are of no more than minor importance in themselves. They become significant to the extent that they may be seen in relation to the means by which they were arrived at, and to the factors by which this process was moulded.

The central factors in the case described may be summarised as follows:

- the nature of the questions upon which the research was based in relation to my previous lack of experience in asking question of this type;

- my lack of previous direct experience of social and economic relations in rural Bangladesh, and the complexity of these relations themselves;

- the general state of theory seeking to explain these relations, and following on from this;

- the absence of clearly agreed and adequate procedures for stratifying populations;

-the 'shape' initially imposed upon the research by the need to satisfy a funding agency;

- the time and resources at my disposal.

As the process unfolded, the interaction between certain of these factors assumed critical importance, and demanded that decisions be taken. In particular:

-my initial perception of the problem to be investigated was modified by direct exposure to the relationships being investigated;

- research procedures which appeared quite sound on paper had to be adapted in the light of unforeseen circumstances, and the time which in practice proved necessary to pursue certain lines of enquiry;

-the time available also dictated that procedures which would have been more satisfactory from a 
theoretical point of view. had to make way for less adequate alternatives.

The outcome is a set of procedures and a piece of research which leave a lot to be desired: and readers who have not undertaken fieldwork themselves. might conclude that the main explanatory factor was my own state of disorganisation. But whilst not seeking to absolve myself from personal responsibility. I would suggest that most fieldworkers. if pressed. would have similar 'confessions' to make. The best laid plans can never adequately plot the course of a piece of fieldwork in advance. Indeed. in one sense at least. the whole exercise would largely be a waste of time if they could. The need to iterate between initial ideas and subsequent experience: between partly worked out theoretical positions. and direct exposure to the working of rural society; and above all. between the ends to which a piece of research is directed. and the means at the researchers disposal. must in practice figure strongly in the experience of any fieldworker.

What in conclusion. does all of this tell us about the possibilities of Rapid Rural Appraisal? The simple and immediate answer would appear to be that methods defined as rapid on any absolute scale. would not have lent themselves to the solution of the type of problem which has been posed here. My account will have indicated that information gathered rapidly would. in many instances. have been incorrect: and leaving this aside. that the use of one or two simple indicators in isolation. would almost certainly have served the cause of confusion more readily than that of clarification.

RRA in this sense must therefore be ruled out. but the potential for relatively quicker and more efficient approaches remains. Demystifying exercises of the type attempted here represent an essential first step in this direction. by attacking the isolation of the individual researcher. and providing a basis for discussion of the problems which generally remain concealed behind formalistic presentations of 'method'. Only when such problems are subjected to more general scrutiny will it be possible to determine how far we can move towards answering the challenge which RRA quite legitimately presents.

\section{References}

Agricultural Census Wing. Bangladesh Bureau of Statistics, 1980. Bangladesh Agricultural Census, 1977. Preliminary Results, Government of Bangladesh

Arens, J., and J. van Beurden. 1977. Jhagraphur, Poor Peasants and Women in a Village in Bangladesh. Third World Publications, Birmingham

Barnett. A.. 1979. 'R apid Rural Appraisal, A Personal View of The First IDS Workshop. mimeo

Howes, M. 1979. 'Stratifying a Rural Population. Trade-offs between Accuracy and Time. Paper presented at Rapid Rural Appraisal Conference, 4-7 December 1979. mimeo

Institute of Nutrition and Food Science, 1977. Nutrition Survey of Rural Bangladesh 1975-6, Dacca, Bangladesh

Jannuzi, F. and J. Peach, 1977. Report on the Hierarchy of Interests in Land in Bangladesh, USAID. Washington

Longhurst. R.. 1979. 'Assessing Economic Stratification in Rural Communities. Paper presented at Rapid Rural Appraisal Conference, 4-7 December 1979. mimeo

Moore, M. 1979. 'Beyond the Tarmac Road: A (Nutshell) Guide for Rural Poverty Watchers. Paper presented at Rapid Rural Appraisal Conference, 4-7 December 1979. mimeo

- with M. Lipton. 1972. :The Methodology of Village Studies in Less Developed Countries. Discussion Paper 10. IDS. Sussex

Patnaik, U.. 1976. 'Class Differentiation within the Peasantry'. Economic and Political Weekly, Review of Agriculture, September. 